\title{
Utilização de Técnicas de Orçamento de Capital Nas Concessionárias de Mossoró, RN
}

\section{Use of Capital Budget Techniques in Mossoró, RN Concessioners}

\author{
Arthur William Pereira da Silva ${ }^{1}$, Alípio Ramos Veiga Neto ${ }^{1}$, Fábio Chaves Nobre ${ }^{2}$, Brenda Nathália Fernandes \\ Oliveira $^{3}$, Francisco Igo Leite Soares ${ }^{4}$, Alda Karla do Vale Jataí ${ }^{1}$ \\ ${ }^{1}$ Universidade Potiguar, UnP, Brasil \\ ${ }^{2}$ Universidade Federal Rural do Semi-Árido, UFERSA, Brasil \\ ${ }^{3}$ Universidade Norte do Paraná, UNOPAR, Brasil \\ ${ }^{4}$ Faculdade Diocesana de Mossoró, FDM, Brasil \\ Correspondência: Arthur William Pereira da Silva. Endereço: Endereço: Av. Alberto Maranhão, 1751, Centro, \\ Mossoró, RN CEP 59600005. Tel.: 5584 3315-4924. E-mail: arthurwilliamadm@ @otmail.com
}

Recebido: 14 de dezembro de 2016 Aceito: 21 de setembro de 2017 Publicado: 31 de outubro de 2017

DOI: http://dx.doi.org/10.21714/1679-18272016v14n2.p413-421

\begin{abstract}
Resumo
A necessidade de atingir a máxima eficiência e eficácia pelas organizações cresce na medida em que a concorrência aumenta. O setor automobilístico mossoroense apresenta alta concorrência, o que obriga as empresas buscarem cada vez mais a otimização de suas atividades. Para tais metas serem atingidas faz-se importante a utilização dos métodos de orçamento de capital para evitar perdas e diminuir os custos na escolha do melhor entre dois ou mais novos projetos. Buscou-se mensurar, através de pesquisa descritiva dirigida à totalidade das concessionárias de carros novos que atuam em Mossoró, a utilização das ferramentas da administração financeira relativas à análise de viabilidade econômica de novos projetos, tais como: Valor presente líquido (VPL); Taxa Média de Retorno (TMR); Taxa Interna de Retorno (TIR); Taxa Interna de Retorno Modificada (TIRM) e o Período de Recuperação do Investimento (Payback). Os resultados mostraram quanto à análise realizada pelas empresas que determina a aceitação de um novo projeto, que $9 \%$ utilizavam o período de payback como técnica para nortear as suas decisões, e 91\% não utilizavam técnicas para esse fim. Portanto, conclui-se que $91 \%$ da gerência financeira do setor automobilístico de Mossoró ainda têm suas decisões sobre escolha de novos projetos baseados em dados empíricos.
\end{abstract}

Palavras-chave: Orçamento de capital. Viabilidade econômica. Técnicas de orçamento de capital. Setor automobilístico.

\begin{abstract}
The need to achieve maximum efficiency and effectiveness by organizations grows as competition increases. The Mossoro an automotive sector has high competition, which forces companies to seek more and more to optimize their activities. For these goals to be achieved, it is important to use capital budgeting methods to avoid losses and lower costs in choosing the best between two or more new projects. The aim was to measure the use of financial management tools related to economic viability analysis of new projects, such as: Net present value (NPV), through a descriptive research directed to all the car dealerships, which operate in Mossoró. Average Return Rate (RRT); Internal Rate of Return (IRR); Modified Internal Rate of Return (TIRM) and the Investment Recovery Period (Payback). The results showed that, according to the companies' analysis, a new project was accepted, $9 \%$ used the payback period as a guiding technique for their decisions, and $91 \%$ did not use techniques for this purpose. Therefore, it is concluded that $91 \%$ of the financial management of the Mossoró auto industry still have their decisions about choosing new projects based on empirical data.
\end{abstract}

Keywords: Capital Budget. Economic Viability. Technical Capital Budget. Automotive Industry.

Esta obra está licenciada sob uma Licença Creative Commons Attribution 3.0

\section{Introdução}

A maximização do lucro, a competitividade e a escassez de recursos incitam as empresas a utilizarem da maneira mais eficaz e eficiente o seu capital. Dentro desse quadro a falta de planejamento financeiro pode ocasionar prejuízos para estas organizações. 
Na literatura atual encontram-se técnicas de orçamento de capital que norteiam os empresários quanto à tomada de decisões em novos investimentos nas organizações. Essas técnicas são embasadas em índices e naturezas de investimentos diversos que promovem o direcionamento dos recursos a curto, médio ou longo prazo. A análise desses índices pode se tornar um fator determinante para injeção de recursos financeiros em projetos com taxas de retorno significativas.

A partir daí, as organizações passam a contar com um facilitador na tomada de decisões quanto a investimentos de capital, mas na ausência do mesmo, o empirismo pode vir a substituir essas técnicas ou, até mesmo decisões individuais baseadas somente em experiências anteriores, podem se tornar um mecanismo na tomada de decisão de novos investimentos. Dentro desse contexto, lança-se a questão norteadora deste estudo: Quais são os principais fatores que orientam os empresários quanto à tomada de decisões em novos investimentos nas organizações em análise?

Esta pesquisa objetivou realizar uma análise da utilização das técnicas de orçamento de capital empregadas na etapa de avaliação das alternativas do processo de orçamento de capital, no segmento de concessionárias de carros novos da cidade de Mossoró.

O processo de orçamento de capital para novos investimentos tem uma enorme importância para uma organização, pois através do mesmo se diminui os riscos do investimento, gerando mais segurança para os investidores.

Através desta pesquisa buscou-se verificar a utilização das técnicas de orçamento de capital no segmento de concessionárias de carros novos da cidade de Mossoró, no Rio Grande do Norte, escolhido devido à sua grande expansão nos últimos anos. De acordo com dados do DETRAN-RN, em janeiro de 2010 a cidade de Mossoró contava com uma frota de 90.926 veículos (MOURA, 2011). Já no mês de abril de 2016 a quantidade de veículos na cidade aumentou para 140.882 , registrando dessa forma, um aumento de quase 50.000 veículos, ou $54,9 \%$ da frota, dentro de um período de pouco mais de seis anos (DETRAN-RN, 2016). Essa expansão gera a necessidade de novos projetos para a ampliação dos espaços de venda, e para aumento na quantidade de máquinas, ferramentas e mecânicos nas oficinas autorizadas que cada concessionária mantém. Projetos esses que, segundo Gitman (2010), devem ser selecionados de acordo com as técnicas de orçamento de capital.

A pesquisa mostrará o nível da utilização das técnicas de orçamento de capital pelas empresas do segmento de concessionárias de carros novos na cidade de Mossoró.

\section{Orçamento de Capital}

Quando uma organização decide realizar um investimento de longo prazo, ela compromete parte relevante de seus fundos com o novo projeto, surge dessa premissa a necessidade de se estabelecer métodos e procedimentos para analisar e escolher entre as várias opções de novos investimentos, aqueles que irão trazer os maiores retornos e gerar os menores investimentos iniciais possíveis. A esse processo de avaliação e seleção de projetos de investimentos de longo prazo, Gitman (2010) define como orçamento de capital.

\section{Téenicas de Orçamento de Capital}

Diversas são as técnicas de orçamento de capital utilizadas para nortear a tomada de decisões em novos projetos, a sua principal função é selecionar os projetos com o melhor custo benefício possível. Essas técnicas são utilizadas em vários lugares do mundo para analisar a viabilidade e lucratividade de investimentos em novos projetos das mais diferentes naturezas. Em posse de projeções futuras de fluxo de caixa o administrador financeiro pode aplicar técnicas de orçamento de capital que vão evidenciar as vantagens e desvantagens de investir em determinado projeto. Com o grau de competitividade do mercado global, as empresas procuram cada vez mais minimizar suas despesas e perdas e maximizar as suas receitas para se manterem lucrativas. As técnicas de orçamento de capital se inserem nesse contexto na medida em que possibilitam uma análise mais criteriosa quanto ao investimento em novos projetos, levando em consideração, por exemplo, o tempo que o novo projeto vai demorar para retornar o investimento inicial. Informações como essas são de suma importância para subsidiar a tomada de decisão empresarial, no processo de seleção de projetos que venham a atender os objetivos financeiros da empresa.

\subsection{Taxa média de retorno (TMR)}

Groppelli e Nikbakht (2002) afirmam que a TMR determina a lucratividade de um projeto. Segundo os autores "a ideia básica é comparar os lucros contábeis líquidos com os custos iniciais de um projeto, adicionando todos os lucros líquidos futuros e dividindo-os pelo investimento médio".

A fórmula da Figura 1 é utilizada para calcular a taxa média de retorno (TMR): 


$$
\mathrm{TMR}=\frac{\text { Média dos lucroslíquidos anuais futuros }}{\text { Metade do investimento inicial }}
$$

Figura 1: Fórmula da taxa média de retorno.

Fonte: Groppelli e Nikbakht, 2010.

Ainda segundo Groppelli e Nikbakht (2002) essa técnica não é recomendada para a análise financeira, pois apresenta uma série de lacunas frente à realidade, tais como:

- A TMR não considera o valor do dinheiro no tempo.

- A TMR usa o lucro contábil e não o fluxo de caixa; ela ignora a depreciação como uma fonte de entrada de caixa.

- A TMR desconsidera a sequência cronológica dos lucros líquidos.

\section{2 período de recuperação do investimento (payback)}

Para uma empresa investir em um novo projeto, é necessário realizar um desembolso de capital, por esse motivo quanto mais rapidamente o novo projeto retornar para a empresa o valor investido, mais atraente será a sua implantação para a organização, mesmo porque o capital que está sendo investido tem um custo, sendo ele de terceiros a empresa pagará juros, quanto mais demorado for o período de retorno do investimento mais juros serão pagos e mais caro será o custo do novo projeto, se o capital for próprio existe o custo de oportunidade, ou seja, a empresa está deixando de investir em outro projeto que poderia gerar mais lucro para continuar investindo no projeto que já foi implantado.

Segundo Gitman (2010), o payback é o tempo necessário para que a empresa recupere o investimento inicial em um projeto, calculando a partir das entradas de caixa. Esse tempo pode ser maior ou menor, esse fator é levado em consideração na tomada de decisão.

\subsubsection{Cálculo do Payback}

Gitman (2010) propõe duas maneiras diferentes de se calcular o período de recuperação do investimento, uma forma quando as entradas de caixa forem uma anuidade e outra forma quando as entradas de caixa forem compostas por uma série mista.

Quadro 1: Cálculo do Payback

\begin{tabular}{|c|l|}
\hline \multicolumn{1}{|c|}{ ANUIDADE } & \multicolumn{1}{c|}{ SÉRIE MISTA } \\
\hline $\begin{array}{l}\text { O período de payback pode ser encontrado dividindo- } \\
\text { se o investimento inicial pela entrada de caixa anual. }\end{array}$ & $\begin{array}{l}\text { As entradas de caixa anuais precisam ser acumuladas } \\
\text { até a recuperação do investimento inicial. }\end{array}$ \\
\hline
\end{tabular}

Fonte: Gitman, 2010.

\subsubsection{Critérios de Decisão}

Gitman (2010) afirma que o período máximo de recuperação do investimento aceitável é definido pela administração de cada empresa, dessa forma se o período de payback de um projeto for menor do que o máximo aceito pela empresa, ele pode ser selecionado. Se o período de payback do projeto for maior do que o máximo aceito pela empresa, o projeto deve ser recusado.

\subsubsection{Vantagens e Desvantagens da Utilização}

Segundo Gitman (2010) esse método é utilizado por empresas de todos os portes, nas grandes para avaliar a viabilidade de projetos de baixo valor, enquanto nas pequenas para avaliar a maioria dos projetos. Essa técnica apresenta algumas vantagens em relação à TMR, ela considera os fluxos de caixa e não os lucros contábeis. Além de considerar em sua aplicação o valor do dinheiro no tempo. Porém a grande desvantagem dessa ferramenta é a subjetividade da determinação do período adequado de payback.

\subsection{Valor Presente Líquido (VPL)}

Segundo Gitman (1997) o valor presente líquido (VPL) é uma técnica sofisticada de análise de orçamento de capital, obtida subtraindo-se o investimento inicial de um projeto do valor presente das entradas de caixas, descontadas a uma taxa igual ao custo de capital da empresa.

Alguns autores consideram a técnica do valor presente líquido sofisticada por considerar o valor do dinheiro no tempo descontando os fluxos de caixa da empresa a uma taxa de custo desse capital, onde será fornecido o valor do retorno mínimo adquirido ao final de um projeto de investimento. 
O pagamento imediato é conhecido com certeza, ao passo que as entradas futuras são apenas estimativas. Assim sendo precisamos conhecer a relação entre um dólar hoje e um dólar (possivelmente incerto) no futuro, antes de decidirmos quanto ao projeto (ROSS; WESTERFIELD; JAFFE, 1995).

Essa relação conceituada por Ross, Westerfield e Jaffe (1995) é chamada de conceito de valor do dinheiro no tempo. Essa relação auxilia na tomada de decisões e nas escolhas de projetos de investimentos com valores previstos de retorno para identificar o projeto viável conforme as perspectivas da empresa.

O valor presente líquido pode ser utilizado para cálculos de investimento com um único período como também de múltiplos períodos.

$$
V P L=\sum_{t=1}^{n} \frac{F C t}{(1+r)^{t}}-F C_{0}
$$

Figura 2: Fórmula do valor presente líquido

Fonte: Gitman, 2010.

Com a utilização dessa técnica é possível transformar os valores monetários futuros e projetados do fluxo de caixa em valores atualizados e com isso subtrair o investimento inicial, que é um valor monetário atual, descobrindo qual o retorno obtido com o projeto de investimento no final do período estimado no fluxo de caixa.

Essa técnica é utilizada como índice considerável na escolha do investimento em um projeto A ou B. Segundo Gitman (1997) se o VPL for maior que zero, aceita-se o projeto; se o VPL for menor que zero, rejeita-se o projeto. Seguindo esse critério, é possível prever e avaliar qual o retorno do investimento ao final do projeto, evitando assim, dispêndio de capital inadequado.

Se o VPL for maior que zero a empresa obterá um retorno maior do que seu custo de capital. Com isto, estaria aumentando o valor de mercado da empresa e, consequentemente, a riqueza dos seus proprietários (GITMAN, 1997, p. 330).

Segundo Gitman (1997), o VPL é a melhor técnica para definir a tomada de decisões já que o valor positivo do caixa será reinvestido na empresa com o custo de capital encontrado no modelo CAPM, onde apresenta o custo de capital mais fiel a situação da empresa por considerar o risco de mercado.

\subsection{Taxa Interna de Retorno (TIR)}

Autores como Gitman (1997) comprovam que a TIR é uma das técnicas sofisticadas mais usadas para avaliação de alternativas de investimentos. É a taxa de desconto que iguala o valor presente das entradas de caixa ao investimento inicial referente a um projeto, resultando, desse modo em um VPL nulo, define Gitman (1997).

A ideia básica por trás da TIR é a de que se procura calcular um número que sintetize os méritos de um projeto. Esse número não depende da taxa de juros vigente no mercado de capitais. É por isso que é chamada de taxa interna de retorno; o número calculado é interno e intrínseco ao projeto, e não depende de qualquer outra coisa além dos fluxos de caixa do projeto (ROSS; WESTERFIELD; JAFFE, 1995).

Segundo Gitman (2010) o cálculo da TIR é feita com a seguinte fórmula (Figura 3):

$$
\sum_{t=1}^{n} \frac{F C}{(1+T I R)} t=F C_{0}
$$

Figura 3: Fórmula da taxa interna de retorno.

Fonte: Gitman, 2010.

O cálculo será realizado por tentativa e erro ou utilizando uma calculadora financeira. Vendo que a utilização da fórmula para cálculos de fluxos de caixa de série mista requer bastante tempo, já que utilizamos a técnica de tentativa e erro adotando valores quaisquer para o VPL ser nulo. Nesses casos podemos utilizar calculadoras financeiras para facilitar o cálculo.

Com o VPL nulo, identificamos que o valor do investimento inicial se torna igual ao dos valores presentes das 
entradas de caixa a uma TIR maior que o custo de capital. Adotando o critério de decisão "aceitar-rejeitar", se a TIR for maior que o custo de capital, aceita-se o projeto; se for menor rejeita-se o projeto.

Também deve estar claro que o VPL é positivo para taxas de desconto inferiores à TIR, e negativo para taxas de desconto superiores à TIR. Isto significa que, se aceitarmos projetos como este quando a taxa de desconto é inferior à TIR, estaremos aceitando projetos com VPL positivo. Assim a regra da TIR coincidirá perfeitamente com a regra do VPL (ROSS; WESTERFIELD; JAFFE, 1995).

Para essa análise das regras coincidentes do VPL e TIR, são usadas para exemplos simples onde os fluxos de caixa são pequenos. Em situações de projetos complexos alguns problemas podem surgir e os dois índices devem ser analisados separadamente.

\subsection{Taxa interna de retorno modificada (TIRM)}

O método da TIRM é considerado como um método melhorado da TIR. Podemos identificar na utilização da TIR que, em projetos com valores de fluxos de caixas com sinais diferentes, mais de uma taxa de retorno é encontrada proporcionando uma divergência de taxas a serem consideradas. Os fluxos de caixa positivo são reinvestidos a taxa de retorno no projeto, sendo essa divergente da taxa de desconto, causando resultado menos confiável e podendo comprometer a tomada de decisão quanto à aceitação ou rejeição do projeto. Segundo Ross, Westerfield e Jaffe (1995), a existência de múltiplas taxas, embora matematicamente corretas, não tem significado financeiro relevante para o processo de decisão de investimento.

O método da TIRM resgata a vantagem da facilidade de interpretação dos resultados na forma de taxa; possibilita a comparação entre as diversas taxas de mercado; e obtém uma taxa de retorno do investimento mais realista.

O método baseia-se nos valores de fluxo de caixas separadamente por seus sinais. Os valores intermediários positivos são calculados à taxa de reinvestimento compatível com as do mercado, trazendo-os para o valor futuro no último período do fluxo de caixa. Os valores intermediários negativos são trazidos a valor presente, com uma taxa de financiamento compatível com as do mercado. Com esses valores trazidos para o valor presente e para $\mathrm{o}$ valor futuro usamos o cálculo de juros compostos para solucionarmos a taxa interna de retorno.

Muitos acreditam que a TIRM é uma taxa híbrida, visto que é uma mistura do método do VPL, que capitaliza os fluxos de caixa intermediário ao custo de capital, e do método da TIR (DAMODARAN, 2004, p. 267).

Nos casos de processos decisoriais para escolha da implementação de projetos de investimentos, é necessário a análise da TIRM, que será equiparada a utilização do VPL para escolha do investimento. Considerando a taxa de custo de capital em relação à TIRM, se a primeira for menor ou igual à segunda, o projeto se torna aceitável, caso contrário não se considera viável aceitar o projeto.

\section{Metodologia}

A pesquisa realizada neste trabalho é de natureza descritiva, pois buscou descrever e analisar a situação da utilização de um conjunto de técnicas em um segmento específico, e através disso validar ou não as hipóteses levantadas a priori. Segundo Bertucci (2009), pesquisas descritivas além de descreverem as situações buscam, entre outros objetivos, levantar hipóteses ou possibilidades sobre essas situações.

A técnica utilizada pela pesquisa realizada foi o levantamento, pois a pesquisa buscou obter informações de um segmento específico de maneira direta, para através de uma análise chegar às conclusões e a validação ou não das hipóteses levantadas. Na técnica do levantamento

Basicamente, procede-se a solicitação de informações a um grupo significativo de pessoas, acerca do problema estudado para, em seguida, mediante análise quantitativa, obterem-se as conclusões correspondentes aos dados coletados (BERTUCCI, 2009, p.54).

Segundo Bertucci (2009) existem três níveis de unidade de análise: o nível macro, o nível da organização ou o nível do indivíduo, sendo que no nível de análise macro são realizadas pesquisas em nível de economia nacional, ou de um dos muitos setores econômicos. Dessa forma, considerando o posicionamento da autora a pesquisa realizada neste trabalho se enquadra como de unidade de análise macro, pois busca mensurar um comportamento inerente a todo o segmento de concessionárias de carros novos da cidade de Mossoró. Segmento esse que foi selecionado devido ao seu notório ritmo de crescimento nos últimos anos, fato que implica uma série de investimento em novos projetos, que por sua vez requer, segundo Gitman (2010), uma análise e seleção dos novos projetos de acordo com as técnicas de orçamento de capital. 
A ferramenta utilizada para a coleta de dados relativos à pesquisa proposta neste trabalho foi o questionário devido a sua metodologia direta e objetiva.

A pesquisa foi realizada através de um senso com as 11 (onze) empresas que compõe o segmento de concessionárias de veículos novos da cidade de Mossoró, tornando desnecessário qualquer tipo de cálculo amostral, e estabelecendo o nível de confiabilidade da pesquisa em $100 \%$.

\section{Análise dos Dados}

Conforme tabulação dos resultados da aplicação da pesquisa, foi constatado que $64 \%$ das empresas estão atuando no mercado no máximo há 5 anos, sendo $18 \%$ delas com mais de 30 anos, exemplificado pela Figura 4:

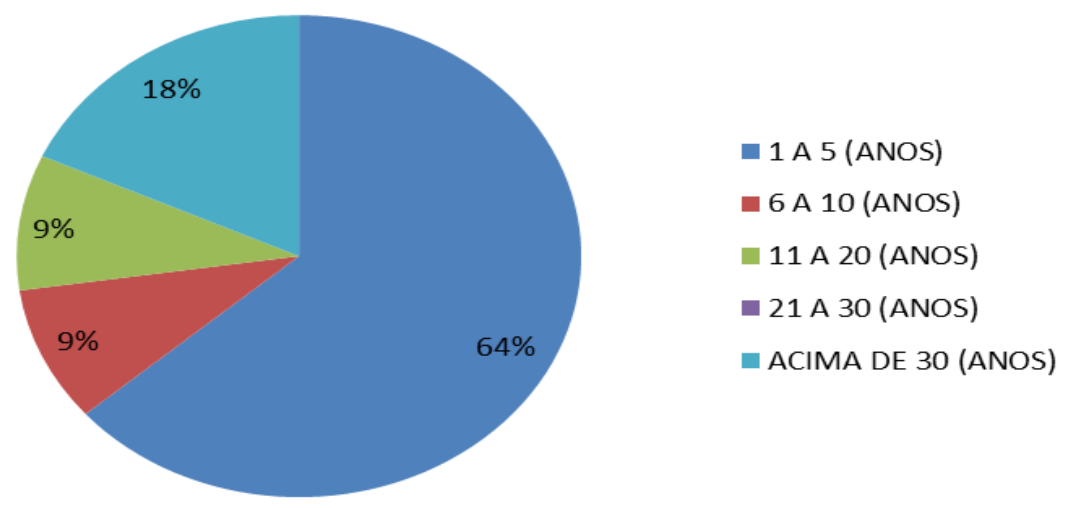

Figura 4: Atuação no mercado

Fonte: Própria

Como mostra a Figura 5,64\% das empresas entrevistadas apresentam faturamento médio mensal maior que R \$ 360.000,00 e apenas 9\% das empresas têm faturamento médio de até R\$360.000,00. Valendo-se da classificação de porte de empresas do SEBRAE (n.d) por receita bruta anual, pode-se definir que $9 \%$ das empresas entrevistadas são microempresas e $64 \%$ são empresas de pequeno porte.

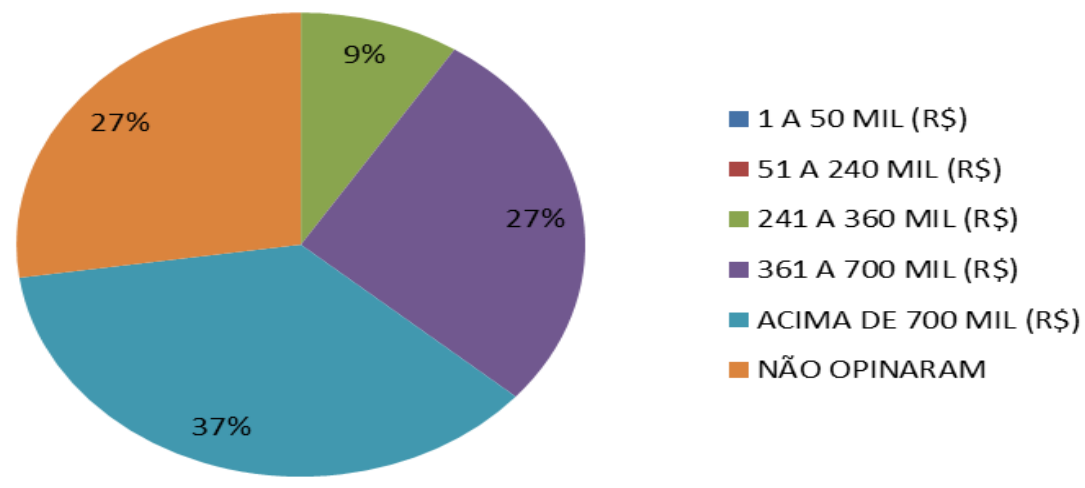

Figura 5: Faturamento médio mensal Fonte: Própria

A Figura 6 mostra que entre as empresas, $73 \%$ não detêm um profissional responsável pelo processo de tomada de decisões quanto aos investimentos em novos projetos. Nessas empresas o processo de tomada de decisões é realizado pelo proprietário da organização.

Quanto à análise realizada pelas empresas que determina a aceitação de um novo projeto, $9 \%$ utilizam o período de payback como técnica para nortear as suas decisões e 91\% não utilizam técnicas para esse fim alegando realizar apenas o estudo do potencial de mercado e renda per capita da região. Resultados que evidenciam uma baixa adesão dos micro e pequenos empresários à utilização das técnicas de orçamento de capital, convergindo com os resultados da pesquisa sobre utilização de técnicas de orçamento de capital desenvolvida por Peñaloza e Guerra (2006) em fortaleza no Ceará, na qual foram pesquisadas 183 empresas; 45 do setor industrial, 86 do setor comércio e 52 do setor serviços. Dentre as quais foi identificado que apenas $32,3 \%$, daquelas que são classificadas como micro ou pequenas empresas utilizam alguma técnica de orçamento de capital. Para Peñaloza e Guerra (2006) essa baixa adesão dos micro e pequenos empresários às técnicas de orçamento de capital indica 
que estes estão focados na gestão de curto prazo, e despreparados ou despreocupados para enfrentar a gestão de longo prazo.

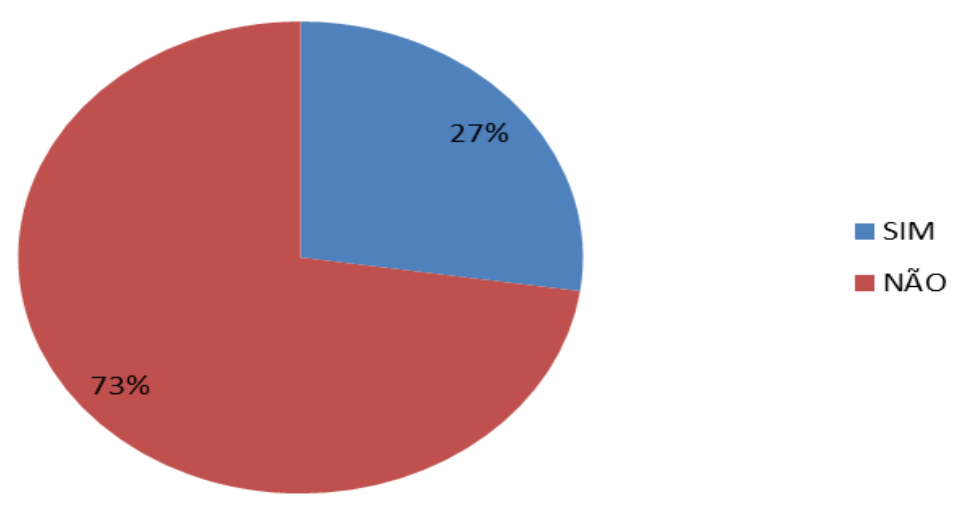

Figura 6: Profissional responsável pela tomada de decisões em novos projetos Fonte: Própria

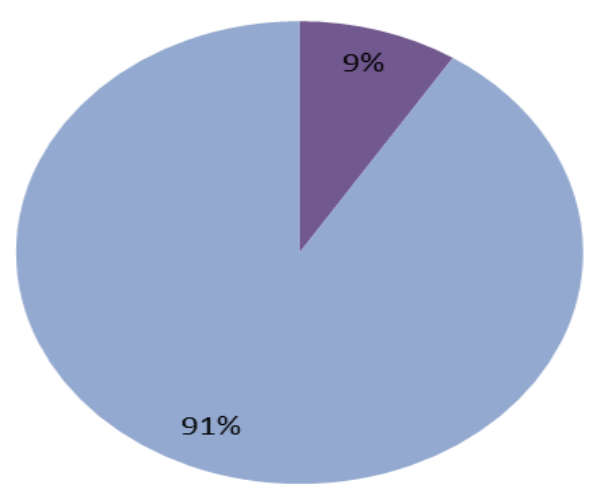

$$
\begin{aligned}
& \text { VPL } \\
& \text { TIR } \\
& \text { TIR-M } \\
& \text { PBCK } \\
& \text { PBCK DESC } \\
& \text { IL } \\
& \text { NÃO UTILIZA }
\end{aligned}
$$

Figura 7: Técnica utilizada para aceitar um novo projeto

\section{Fonte: Própria}

Para cálculo do período a ser retornado o valor investido em um projeto, $91 \%$ das empresas não utilizam nenhuma técnica existente para mensurar tal período. Dentro dos participantes, 9\% utilizam o Payback como técnica utilizada para mensuração do período de retorno. Como mostra a Figura 8.

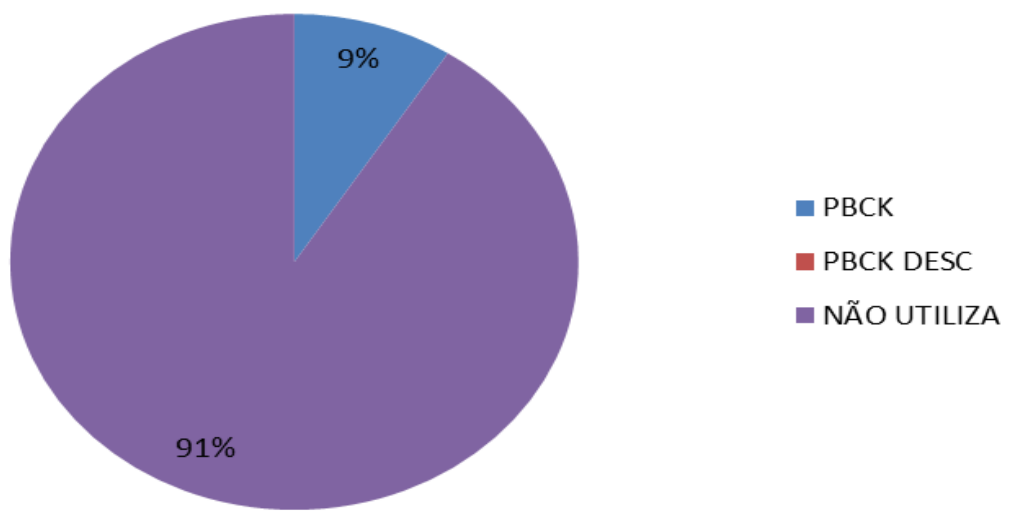

Figura 8: Técnica utilizada para mensurar período de retorno

Fonte: Própria

A Figura 9 mostra que a taxa de retorno mínimo esperado de um investimento não é utilizada como técnica por 91\% das empresas pesquisadas. Os outros 9\% utilizam a taxa de juros paga pelo custo do capital de terceiros como taxa de retorno. 


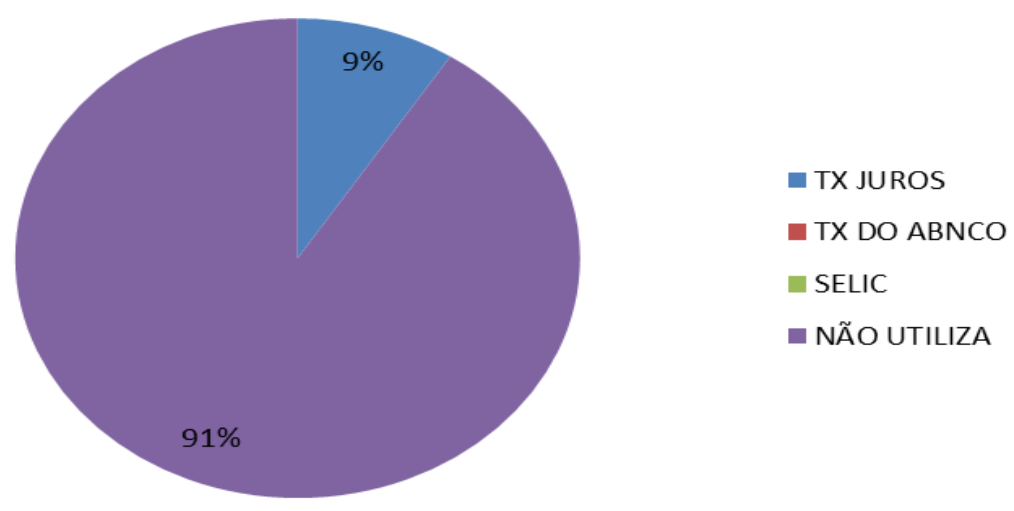

Figura 9: Taxa utilizada como retorno mínimo

Fonte: Própria

Das fontes de capital existentes, $82 \%$ das empresas utilizam capital de terceiros, e somente $18 \%$ utilizam capital próprio como fonte para dispêndio de capital em projetos de investimentos. Peñaloza e Guerra (2006) identificaram em sua pesquisa que o uso das técnicas de orçamento de capital depende da estrutura de capital da empresa. Em sua pesquisa perceberam que empresas que utilizam capital de terceiros faziam uso técnicas de orçamento de capital. Isso devido às exigências dos órgãos financiadores. Porém, apesar de $82 \%$ das empresas analisadas nesta pesquisa afirmarem utilizar capital de terceiros, apenas $9 \%$ do total das empresas dizem utilizar técnicas de orçamento de capital.

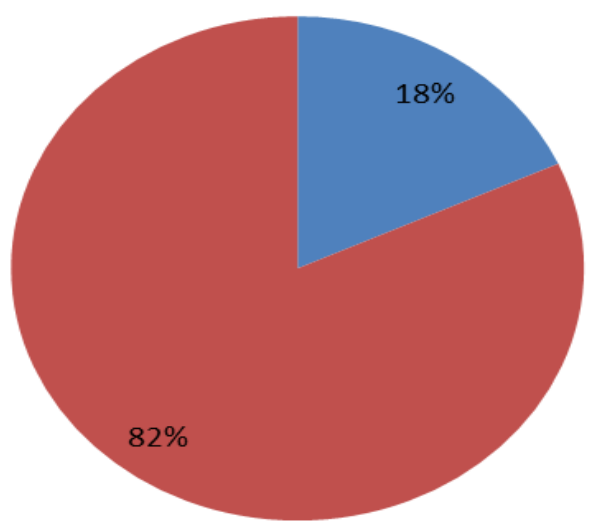

- capital próprio

- capital terceiro

Figura 10: Fontes de capital Fonte: Própria

\section{Conclusão}

Os resultados da pesquisa mostram que $64 \%$ das empresas pesquisadas têm poucos anos de atuação no mercado, entre um e cinco anos, fato que explicita a recente tomada de decisão a respeito da viabilidade econômica e orçamentária dessas novas empresas. Porém, o estudo também evidencia que apenas $9 \%$ das empresas utilizam uma técnica de orçamento de capital para avaliar seus novos projetos, sendo utilizada apenas a mais simples, o período de recuperação do investimento (PAYBACK), que apesar de ser útil para mensurar o período em que o novo projeto vai trazer o retorno do investimento, apresenta muitas deficiências, uma delas o fato de não considerar o valor do dinheiro no tempo, prejudicando assim a qualidade da análise financeira. Essa baixa adesão dos micro e pequenos empresários a utilização das técnicas de orçamento de capital indicam uma gestão focada no curto prazo e despreparada para o longo prazo.

Quando questionados sobre a utilização de técnicas de orçamento de capital na análise da viabilidade financeira de novos projetos, $91 \%$ dos gerentes assumiram ter total desconhecimento da existência de qualquer um dos métodos existentes. Uma peculiaridade identificada no estudo foi que o resultado é o mesmo nas microempresas e nas empresas de pequeno porte. Portanto, conclui-se que $91 \%$ da gerência financeira do segmento de concessionárias de carros novos de Mossoró-RN ainda têm suas decisões sobre escolha de novos projetos baseados em dados empíricos, fato que não os impede de obter lucratividade, porém facilita a geração de perdas, custos e despesas desnecessárias. 


\section{Referências}

BERTUCCI, J. L. O. Metodologia básica para elaboração de trabalhos de conclusão de curso (TCC): (ênfase na elaboração de TCC de pós-graduação Lato Sensu.) 2. reimpr. São Paulo: Atlas, 2009.

DAMODARAN, A. Finanças Corporativas: Teoria e Prática. 2. ed. Porto Alegre: Bookman, 2004.

DETRAN. Departamento Estadual de Trânsito. Distribuição da Frota do Rio Grande do Norte, Segundo a Nacionalidade. $2016 . \quad$ Disponível em: http://www2.detran.rn.gov.br/externo/est_nacionalidade.asp?codcidade=1759>. Acesso em: 19 abr. 2016.

GITMAN, L. J. Princípios de administração financeira. 7.ed. São Paulo: Pearson, 1997. Princípios de administração financeira. 12.ed. São Paulo: Pearson, 2010.

GROPPELLI, A. A.; NIKBAKHT, E. Administração Financeira. 2.ed. São Paulo: Saraiva, 2002. Administração Financeira. 3.ed. São Paulo: Saraiva, 2010.

GUERRA, V.; GUERRA, D. S. Uso das Técnicas de Orçamento de Capital em Empresas de Fortaleza: Um estudo exploratório. In: ENCONTRO NACIONAL DE ENGENHARIA DE PRODUÇÃO, 26., 2006, Fortaleza. Anais... Rio de Janeiro: ASSOCIAÇÃO BRASILEIRA DE ENGENHARIA DE PRODUÇÃO, 2006.

MOURA, E. Mossoró conta hoje com mais de 100 mil veículos registrados. Correio da tarde, 2011. Disponível em: http://www.correiodatarde.com.br/editorias/correio_mossoro-60527. Acesso em: 20/10/2011.

ROSS, S. A.; WESTERFIELD, R. A.; JAFFE, J. F. Administração Financeira: (Corporate Finance.). São Paulo: Atlas, 1995.

SEBRAE. SERVIÇO BRASILEIRO DE APOIO ÀS MICRO E PREQUENAS EMPRESAS. Critérios de Classificação de Empresas: MEI - ME - EPP. n.d. Disponível em: < http://www.sebraesc.com.br/leis/default.asp?vcdtexto=4154.> Acesso em: 19 de Abr. 2016. 